
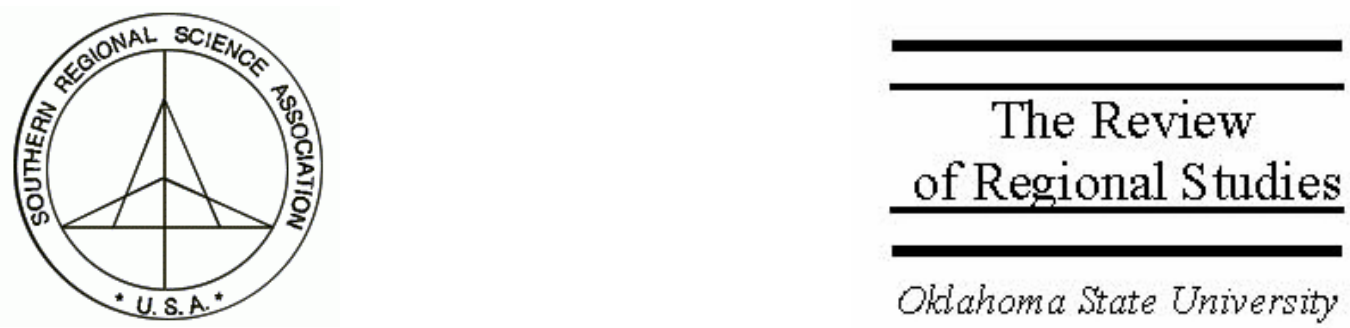

\title{
The Persistence of County High School Dropout Rates in the Rural South, 1970-2000
}

\author{
David A. McGranahan \\ Economic Research Service, U.S. Department of Agriculture, \\ 1800 M Street, NW, Washington, DC 20036, \\ e-mail: dmcg@ers.usda.gov
}

\begin{abstract}
This paper investigates Smith's (1989) thesis that county drop out rates have been selfperpetuating in the rural South, a pattern reinforced by the presence of mining and manufacturing employers with few skill demands. The results show that the associations of mining and manufacturing with high drop out rates, notable as late as 1980, have largely disappeared. But counties with high proportions of female headed families and low young adult (age 25-44) education continue to have little improvement in high schools completion. The extent of perpetuation of low education varies by state, whether due to differences education policies or economic structures.
\end{abstract}

Keywords: Human capital; High school completion rate

JEL classification: R23; J24; N92 


\section{INTRODUCTION}

The proportion of students who complete high school is perhaps the most basic measure of local school success. But as Coleman (1988), Lichter et al. (1993), Israel, Beaulieu, and Hartless (2001), Wenk and Hardesty (1995), and others have made clear, school outcomes are the products not only of schools, but also of the constituent families and the socioeconomic context in which the schools are situated. These authors have focused largely on the role of student family structure and income in determining school success, although Israel, Beaulieu, and Hartless (2001) extend their analysis of the role of social capital in school outcomes to consider the integration of student and family into the community. The present paper follows Smith (1989), DeYoung (1985), and Stallmann et al. (1995) to consider the influence of the local socioeconomic context, particularly the local industry structure, on high school completion rates in the rural (nonmetropolitan) South.

Smith, concerned with continuing low education levels in rural Appalachia, argues that the low-skill needs of the region's employers is perpetuating a "vicious cycle of low levels and qualities of education, severe underutilization and low productivity of labor, low skill demanding employers, and reinforcement of the low standards of investment in human capital” (1989, p. 21). Historically, mining had provided many in the region with low-skill jobs at relatively high rates of pay, which discouraged high school completion. The recent influx of manufacturing did little to mitigate the situation since most of the jobs created by the new plants also placed relatively few demands on skills. Moreover, while some of the staff migrating to the area may have been concerned about local school quality, employers of low-skill workers have little interest in improving local workforce skills as this could undermine the very labor market characteristics that drew them to the area in the first place (see Bowles and Gintis 1976). Smith (1989) argues that rural policy in areas with perpetually high dropout rates should encourage if not subsidize the in-movement and growth of high skill manufacturers.

Ethnographic studies of Appalachian schooling are largely consistent with Smith's (1989) thesis of a perpetuation of low levels and quality of education (e.g., DeYoung 1991; Duncan 1999). However, few studies have examined the role of local industry in this process. Stallman et al. (1995) examine the influences of occupational and industrial structure in their studies of all Virginia counties, but they did not incorporate the concept of inheritance of low education in rural areas. De Young (1985), using 1980 data for Kentucky counties, found that dependence on mining was negatively related to several education variables, including the proportion of $9^{\text {th }}$ graders who finished school; but he also did not consider adult education levels. It appears that Smith's thesis has never been fully examined.

Smith's thesis is particularly interesting since some of his prescription appears to have been followed. Encouraged by subsidies and tax breaks, the auto industry has moved south, bringing with it many suppliers. While these are not high-tech jobs, they typically require at least a high school education. McGranahan (1999) found, moreover, 
that many existing rural manufacturers have raised their educational requirements as they have adopted new technologies and management practices. At the same time, however, manufacturing may be shifting its location to satisfy skill needs. Thus, the auto industry has not moved into the low-education areas once dominated by textiles and apparel (McGranahan 2001).

This suggests that the relationship between manufacturing and high school dropout rates may have changed over time. Where manufacturing once may have been associated with higher dropout rates, this relationship may have been mitigated or even reversed as skill demand has increased. This relationship may have occurred in mining as well, where sophisticated machinery has replaced much mining labor.

This paper explores two aspects of Smith's (1989) thesis for counties in the nonmetropolitan South. The first is the inheritance of low education. How relevant is the presence of a young adult population with low educational attainment to concurrent high school dropout rates? Previous research focused on family structure and poverty or "socioeconomic status" (a combination of education and income) as explanations of high dropout rates. Here, I compare the relative importance of family structure, poverty, and young adult (ages 25-44) education in Census years 1970 through 2000.

The second focus is the influence of local industry structure on high school dropout rates, as this role may have changed over the study period. The expectation is that both manufacturing and mining were associated with high dropout rates early in the study period, but this association weakened over time.

\section{METHODS AND DATA}

The basic model posits that at any point in time, the county high school dropout rate $(D)$ is a function of socioeconomic conditions (SE), industry structure $(I)$, racial/ethnic composition $(R E)$, the level of urbanism, $(U)$ the presence of colleges and universities or the military $(C)$, and recent economic growth $(G)$ :

$$
D=f(S E, I, R E, U, C, G)
$$

Four time points are included in the study, each corresponding with a Census year: 1970, 1980, 1990, and 2000.

For 1980-2000, the dependent measure is the proportion of the population age 16 to 19 that is out of school but without a high school diploma. For 1970, this proportion is only available for the population age 16 to 21 , so that is used. These proportions are not always accurate estimates of the proportion of local students who do not complete high school. The actual proportion will be underestimated to the extent that students over 16 may yet end up without a diploma. At the same time, these measures, particularly the 1970 measure, may overestimate the dropout rate to the extent that recent high school graduates are more likely to leave their counties than are dropouts. 
Socioeconomic conditions include the proportion of children not living in two-parent families, the poverty rate for the residential (non-institutional) population, and the proportion of the young adult population (ages 25-44) with at least a high school diploma or its equivalent. At issue is whether local education levels have a strong bearing on county dropout rates independent of poverty and family structure conditions. Industry is broken down into four categories: agriculture, mining, manufacturing, and other. Four other types of measures are primarily control measures.

1. Racial/ethnic composition. This is reflected in three variables, the proportions of the population who are Black, Hispanic, and Native American in each decade. Although nationally Blacks still have higher dropout rates than Whites, their rates declined relatively rapidly between 1972 and 1990, with most of the decline occurring in the 1980s (National Center for Education Statistics 2003). Greenberg and Teixeira (1998) found that rural Black achievement scores on educational tests had risen substantially between 1975 and 1994, suggesting that improvements extended to rural areas.

2. Urban influence. This is reflected in three dichotomous measures: adjacency to a metropolitan area, the presence in the county of a city of 10,000 or more residents, and the absence of any town of over 2,500 residents. The 1990 measures, derived from Ghelfi and Parker (1998), are used for all the analyses. In a study of Virginia counties, Stallmann et al. (1993) found substantially lower dropout rates in completely rural areas compared with more urban areas.

3. Institutions. Measures are included to reflect the percentages of college students and of armed forces personnel in the 1990 population age 20 to 24 . The presence of a college or university might influence high school completion, particularly as the likelihood of attending college increases with proximity (Gibbs 1998). Also, the dependent variable, the proportion of youth aged 16-19 outside of school but not having a high school diploma, is clearly going to be lower in a county with a substantial number of college freshmen. The military was included as its personnel may also influence county statistics. Data were not available prior to 1990, so the 1990 statistic has been used for all time points under the assumption that the relative sizes of the college and military populations across counties have been relatively stable.

4. Recent growth. Change in county resident employment in the previous decade may affect the dropout rate in opposing ways. ${ }^{1}$ On the one hand, growth in opportunities may draw students out of school and into the labor force, increasing the dropout rate. On the other hand, this growth may make the advantages of high school and further education clearer, decreasing the dropout rate (see Bils and Klenow 2000). The measure used, based on the Censuses, was the $\left(\log _{e}\right.$

\footnotetext{
${ }^{1} \mathrm{~A}$ reviewer suggested this measure.
} 
transform of the) ratio of employment in the year in question divided by the number employed 10 years earlier.

During the 1990s, the Hispanic population grew rapidly in many counties across the South. Drawing on 2000 Census of Population data, Kandel and Cromartie (2004) found that Hispanics in counties with substantial gains in Hispanics had relatively low levels of education (63 percent had not completed high school). Growth in this Hispanic population is likely to have affected not only the county proportion of the population age 25-44 with at least a high school degree, but also the dropout rate. To reflect the change in the Hispanic population, the percentage of the population Hispanic ten years prior was subtracted from the current proportion.

While the aim was to carry out identical analyses for each Census year, several inconsistencies across Censuses preclude exact replication. First, 1970 data on school years completed were available only for the population aged 25 and over. To bridge the 1970 analysis with later analyses, the 1980 analysis was carried out twice, first with the dropout and high school completion rates analogous to the 1970 measures and then with rates analogous to the 1990 and 2000 measures.

The second inconsistency stems from the new industrial classification scheme adopted in the 2000 Census of population, which affected both agriculture and manufacturing categories. For instance, logging was counted as manufacturing under the Standard Industrial Classification (SIC) system used in 1970-1990 but as forestry in 2000, following the North American Industrial Classification System (NAICS). There are other questions about industry comparability over time due to industrial reorganization. In both agriculture and manufacturing, some activities once typically carried out by the enterprise are now being out-sourced. These definitional and organizational changes are on the margins, however, and do not seem to have affected the basic results below. The third inconsistency is that the proportion Hispanic was not available for 1960, so the calculation of the change in Hispanic population, 1960-1970 could not be made for the 1970 analysis.

Unfortunately for the purposes of the present analysis, the education and family structure measures cover the institutional as well as the residential (noninstitutional) populations. With increasing rates of incarceration over the past 20 years, statistics on both county high school dropout rates and young adult education are likely to be affected in counties with juvenile facilities and adult prisons. According to the 2000 Census of Population, the average proportion of the county population age 18 to 64 in a "correctional institution" was 3.3 percent in the study region, with the proportion exceeding 10 percent in 12 percent of the counties. No finer age categories are available, but these proportions were undoubtedly higher among young adults (age 25-44) than among older age groups, as the former are more likely to be incarcerated. The average proportion of the population less than 18 years of age resident in an institution is relatively small - less than 1 percent. But in 2 percent of the counties, the proportion was over 5 percent. This statistic would be much higher for children age 16-17 than for younger children. 
Because the prison population grew so rapidly in the 1980s and 1990s through both expansion and new facility construction (see Beale 1996) and comparable data are not available from earlier Censuses, it was not feasible to use prison population as a control measure in the analyses of dropout rates. Accordingly, 86 of the 953 counties were dropped from the analysis either because the proportion of the population age 18 to 64 in a correctional institution exceeded 15 percent in 2000 or because the proportion less than 18 resident in an institution exceeded 5 percent. The thresholds are somewhat arbitrary. They were the lowest thresholds where the measures themselves were not significant at the .01 level when added to the analyses of 2000 dropout rates.

\section{RESULTS}

The mean county dropout rate declined markedly over the study period in the nonmetropolitan South, although the rate of decline appears to have been more substantial in earlier decades than in 1990-2000 (Table 1). Even with the decline, considerable differences across counties remain: the $90^{\text {th }}$ percentile (18.7 percent) is over three times as high as the $10^{\text {th }}$ percentile (5.6 percent). Moreover, the average in 2000 remained well above the average for nonsouthern nonmetropolitan counties (11.8 percent and 7.8 percent, respectively, using the same exclusion criteria).

The excluded counties do show slower educational gains than the study counties. Average dropout rates declined by 2 percentage points in study counties between 1990 and 2000, but actually rose slightly in the excluded counties, suggesting that the increase in the prison population in the 1990s did affect Census education statistics in counties where prisons were located. ${ }^{2}$

\section{TABLE 1}

High School Dropout Statistics (Ages 16-19) for Counties in the Nonmetropolitan South

\begin{tabular}{lrrrrr}
\hline Statistic & $1970^{1 /}$ & $1980^{1 /}$ & 1980 & 1990 & 2000 \\
\cline { 2 - 6 } & \multicolumn{5}{c}{ Percent } \\
Study counties (N = 867) & 25.5 & 22.2 & 19.6 & 13.8 & 11.8 \\
Mean & 8.0 & 7.2 & 7.1 & 5.4 & 5.2 \\
Std. Deviation & 15.6 & 14.0 & 11.7 & 7.6 & 5.6 \\
10th percentile & 35.6 & 31.5 & 29.1 & 20.8 & 18.7 \\
90th percentile & 58.6 & 49.3 & 50.0 & 38.2 & 33.3 \\
Maximum & &
\end{tabular}

Excluded counties - over 15\% of the population age 18-64 in a correctional facility in 2000 and/ or $5 \%$ of the population age under 18 in an institution $(\mathrm{N}=86)$

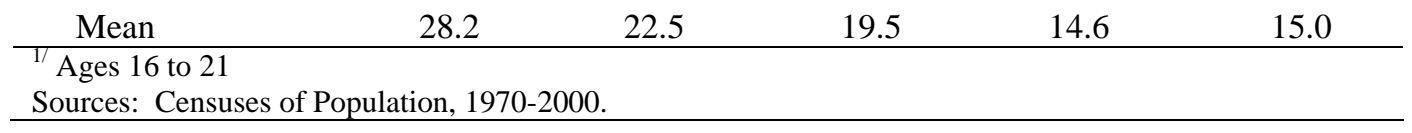

${ }^{2}$ In the study counties, the mean proportion of young adults (age 25-44) with a high school diploma rose from 73 percent in 1990 to 77 percent in 2000. In the excluded counties, the rise was trivial: from 71 percent to 72 percent. 
The means for the independent variables are presented in Table 2. The proportions employed in agriculture, mining, and manufacturing have all declined over time, but the declines have not been parallel. Agriculture's share of employment declined most sharply in the 1970s, when the bulk of the baby boom cohort entered the labor market. The mining employment share actually increased during this period, largely due to the energy crisis, but subsequently dropped by half. The percent employed in manufacturing remained fairly steady until the 1990s. Some of the drop between 1990 and 2000 may reflect the new industrial classification system.

High school completion rates for young adults rose substantially between 1980 and 2000. However, even in 2000, the average proportion with a high school diploma (or G.E.D.) was only slightly above three fourths, quite low in an age when skills matter. While this number seems low compared to the dropout rate averages in 1980 and 1990, the numbers are not inconsistent. As noted earlier, the dropout rate measure does not take into account current students, ages 16-19, who may in the end not receive a high

\section{TABLE 2}

County Means for Independent Variables

\begin{tabular}{|c|c|c|c|c|}
\hline Measures & 1970 & 1980 & 1990 & 2000 \\
\hline \multicolumn{5}{|l|}{ Industry (\%'s) } \\
\hline Agriculture & 12.8 & 8.6 & 7.7 & 5.7 \\
\hline Mining & 2.5 & 3.6 & 2.5 & 1.7 \\
\hline Manufacturing & 25.8 & 25.6 & 23.4 & 19.3 \\
\hline \multicolumn{5}{|l|}{ Socioeconomic context (\%'s) } \\
\hline Children not with both parents & 21.0 & 23.7 & 29.3 & 35.3 \\
\hline Poverty rate & 31.2 & 21.3 & 22.3 & 18.7 \\
\hline H.S. diploma or more (age $25-44)^{1 / 1}$ & 32.4 & 66.0 & 73.5 & 77.2 \\
\hline \multicolumn{5}{|l|}{ Race/ethnicity (\%'s) } \\
\hline Native American & 0.5 & 0.8 & 1.1 & 1.2 \\
\hline Black & 19.2 & 17.4 & 17.0 & 16.8 \\
\hline Hispanic & 4.9 & 4.9 & 5.5 & 7.4 \\
\hline \multicolumn{5}{|l|}{ Urban influence, 1990 (0-1) } \\
\hline Adjacent to metro & 52.8 & & ..(same). & \\
\hline Center of City of 10,000 or more & 20.7 & & ..(same). & \\
\hline Completely rural & 16.1 & & ..(same). & \\
\hline \multicolumn{5}{|l|}{ Institutions, 1990 (\%) } \\
\hline Enrolled in college (age 18-24) & 21.1 & & ..(same). & \\
\hline In military (age 20-24) & 1.1 & & ..(same). & \\
\hline \multicolumn{5}{|l|}{ Change in previous decade } \\
\hline Employment (ln) & 0.07 & 0.33 & 0.09 & 0.11 \\
\hline Hispanic population (pctage pt.) & & 0.5 & 0.6 & 1.9 \\
\hline $\mathrm{N}$ & 867 & & & \\
\hline
\end{tabular}


school diploma and is thus an underestimate of the proportion that do not complete high school. At the same time, those who complete high school in rural areas may be much more likely to migrate to urban areas than those who do not get a diploma.

The county mean proportion of children who do not live in a two-parent family has risen markedly since 1970, to 35 percent in 2000. On average, about 23 percent of children in 2000 lived with either their mother (18 percent) or their father (5 percent). Another 10 percent lived with other relatives, usually grandparents. Two percent did not live with relatives but with other people or in an institutional setting.

Average poverty rates fell in the 1970s, rose slightly in the 1980s, and then fell again to their lowest level by the end of the 1990s. In all, the socioeconomic context has generally improved over time, but fewer children are in two-parent families. This decline may be associated with a rise in dropout rates.

Employment growth has been fairly even over time with the marked exception of the 1970s, the period when much of the baby boom cohort entered the labor market. Up through the 1980s, average nonmetropolitan county growth has been somewhat higher in the South than the rest of the country. However, in the 1990s, this average was slightly lower in the South than elsewhere. The Hispanic proportion of the population grew at about half a percentage point in the 1970s and 1980s, but by nearly 2 percentage points in the 1990s, a sizable increase.

Table 3 presents the results from the dropout rate regressions. In 1970, agriculture, mining, and manufacturing all apparently played a role in perpetuating low educational achievement in the rural South. All three industry measures had strong net effects on the high school dropout rate. By 1980, the picture changed. The coefficients for both agriculture and manufacturing are substantially smaller, with the agriculture measure no longer large enough to attain significance. However, the energy boom of the late 1970s appears to have led to a substantially higher association between the dropout rate and mining employment, even with change in employment between 1970 and 1980 in the equation. This may stem from the very high earnings that workers could gain in mining even without a high school diploma.

The 1980 industry effects are substantially reduced when the analysis is run with the alternative education measures - dropout rate for age 16-19 instead of age 16-21 and high school completion for age 25-44 rather than age 25 and over. The difference appears to be due to the latter substitution, as the results for industry were much the same regardless of which dropout rate was used. Because dropout rates have been declining over time, education statistics for age 25 and over reflect county age structure as well as education. When the proportion of the population age 62 and over was added to the initial 1980 equation, the coefficient for manufacturing dropped to .07 and was no longer significant. The coefficient for mining also dropped, to .21, while the coefficient for agriculture remained near 0 . In short, the results came to resemble those obtained when the high 
school completion measure is limited to age 25-44. Nonetheless, the age-specific education measure appears to provide a better fit to the data. When this measure is used, the age 62 and over variable adds nothing to the variance explained. However, the variance is 4 to 5 percentage points higher than when both the high school completion (age 25 and older) and the age 62 and over variables are in the analysis. This holds for either dropout rate.

All three socioeconomic factors were strongly associated with the high dropout rate in 1970. The proportion of young adults without a high school diploma had a strong correlation with teen-age dropout rates throughout the study period. The relationship is not necessarily straightforward: not being raised in a two-parent household may increase the propensity for students to drop out but, at the same time, some students may drop out when they have children.

\section{TABLE 3}

Standardized Coefficients from OLS Regressions of Dropout Rates, 1970-2000

\begin{tabular}{|c|c|c|c|c|c|}
\hline Independent variables & $1970^{1 /}$ & $1980^{1 /}$ & 1980 & 1990 & 2000 \\
\hline \multicolumn{6}{|l|}{ Industry (\%'s) } \\
\hline Agriculture & $0.15^{* * *}$ & $0.01^{*}$ & -0.01 & -0.05 & $-0.10^{*}$ \\
\hline Mining & $0.14^{* * *}$ & $0.28^{* * *}$ & $0.18^{* * *}$ & -0.07 & -0.06 \\
\hline Manufacturing & $0.27^{* * *}$ & $0.16^{* * *}$ & 0.06 & 0.00 & 0.05 \\
\hline \multicolumn{6}{|l|}{ Socioeconomic context (\%'s) } \\
\hline Children not with both parents & $0.17^{* * *}$ & $0.17^{* *}$ & $0.15^{* *}$ & $0.36^{* * *}$ & $0.23^{* * *}$ \\
\hline Poverty rate & $0.18^{* * *}$ & $0.16^{* * *}$ & $0.09^{*}$ & -0.06 & 0.07 \\
\hline H.S. diploma or more (age $25-44$ ) & $-0.29^{* * *}$ & $-0.37^{* * *}$ & $-0.51^{* * *}$ & $-0.52^{* * *}$ & $-0.42^{* * *}$ \\
\hline \multicolumn{6}{|l|}{ Race/ethnicity (\%'s) } \\
\hline Native American & $-0.09^{* *}$ & $-0.07^{* *}$ & -0.04 & -0.04 & 0.01 \\
\hline Black & $-0.23^{* * *}$ & $-0.39^{* * *}$ & $-0.41^{* * *}$ & $-0.46^{* * *}$ & -0.09 \\
\hline Hispanic & $0.09^{* * *}$ & -0.01 & $-0.14^{* * *}$ & $-0.14^{* * *}$ & $-0.23^{* * *}$ \\
\hline \multicolumn{6}{|l|}{ Urban influence (0-1) } \\
\hline Adjacent to metro & 0.01 & $-0.06^{*}$ & $-0.06^{*}$ & 0.00 & -0.02 \\
\hline Center of City of 10,000 or more & $0.10^{* *}$ & $0.15^{* * *}$ & $0.14^{* * *}$ & $0.09^{* *}$ & $0.05^{* *}$ \\
\hline Completely rural & -0.05 & $-0.07^{*}$ & $-0.07^{*}$ & -0.06 & -0.04 \\
\hline \multicolumn{6}{|l|}{ Institutions, 1990 (\%) } \\
\hline Enrolled in college (age 18-24) & $-0.41^{* * *}$ & $-0.36^{* * *}$ & $-0.25^{* * * *}$ & $-0.26^{* * *}$ & $-0.19^{* * *}$ \\
\hline In military (age 20-24) & 0.01 & 0.02 & 0.04 & 0.04 & 0.03 \\
\hline \multicolumn{6}{|l|}{ Growth in previous decade (ln) } \\
\hline Employment & $0.14^{* * *}$ & $0.11^{* * *}$ & 0.06 & $0.13^{* * *}$ & $0.17^{* * *}$ \\
\hline Hispanic population & -- & 0.01 & -0.02 & 0.03 & $0.18^{* * *}$ \\
\hline $\mathrm{R}^{2}$ (adj.) & 0.46 & 0.52 & 0.50 & 0.40 & 0.39 \\
\hline $\mathrm{N}=867$ & & & & & \\
\hline
\end{tabular}


The net relationship between poverty and high school dropouts has attenuated over time and was not statistically significant in 1990 or 2000. In the 1980 analyses, the size and significance of the poverty coefficient depended on which high school completion measure was used, the one for age 25 and over or the one for age 25-44. As a check on whether the attenuation was largely due to the change in the measure used, the 2000 analysis was rerun using the high school completion rate for ages 25 and over. The coefficient for this education measure was small $(.03)$ and not significant $(\mathrm{p}<.57)$, suggesting that the attenuation was not an artifact of the change in measures.

On the other hand, there is evidence of a continuing strong legacy to low education levels. The coefficients for high school completion rates are strongly negative, however measured, at all four points in time. This inheritance of low education appears to persist independently of local industry structure, poverty, race/ethnicity, employment growth, or any of the other factors in the analysis and provides strong support for Smith's (1989) thesis on the continuity of low education.

Other things being equal, the proportion of the population that is Black is negatively associated with the county dropout rate in these equations. There are, however, two caveats. First, the correlation between the percent Black and the percent of children not raised in two-parent families is extremely high, above 0.80 across the study period. High school completion rates have not been improving in counties with high proportions of Blacks as rapidly as the coefficients for percent Black suggest. The second caveat is that the coefficient for percent Black is only weakly negative in 2000, suggesting that convergence between Blacks and others may have slowed or stopped.

Counties with greater proportions of Hispanics now have lower dropout rates than expected on the basis of other county characteristics. However, counties with rising proportions of Hispanics in their population have greater than expected dropout rates. In effect, the lower dropout rates for Hispanic counties tend to hold only to the extent that the Hispanic population is established.

Although the pattern has been waning, there has been some tendency for counties with cities of 10,000 or more residents to have higher dropout rates than nonmetropolitan counties and for completely rural counties to have lower dropout rates. This is consistent with the study of Virginia counties by Stallman et al. (1995), but the effects are less pronounced in the current study.

The proportion of the population age 18-24 enrolled in college has strong negative effects on the dropout rate. While the presence of a college may depress dropout rates in the local community through demonstration effects, the results more likely reflect the fact that students necessarily have high school diplomas and are included in local area statistics. 
TABLE 4

Standardized Coefficients from Regression of High School

Completion Measures on Industry, 1970-2000

\begin{tabular}{lcccc}
\hline & \multicolumn{3}{c}{ Industry employment (\%) } & \\
\cline { 2 - 4 } Education measure base and year & Agriculture & Mining & Manufacturing & R2 \\
\hline Age 25 and over & & & & \\
1970 & -0.37 & -0.20 & -0.55 & 0.17 \\
1980 & -0.32 & -0.33 & -0.63 & 0.17 \\
Age 25-44 & & & & \\
1980 & -0.31 & -0.40 & -0.55 & 0.17 \\
1990 & -0.33 & -0.35 & -0.44 & 0.14 \\
2000 & -0.28 & -0.24 & -0.25 & 0.10 \\
2000 (1970 industry) & -0.26 & -0.25 & -0.14 & 0.07 \\
\hline
\end{tabular}

Recent employment change is associated with higher rather than lower dropout rates. Students are more likely to stay in school where there are few job opportunities. There is no evidence that this relationship has changed substantially over time.

While agriculture, mining, and manufacturing appear to have little net bearing on high school dropout rates at present, this does not mean that education levels in the counties with these industries have reached parity with the rest of the rural South. All three industries remained associated with relatively low levels of high school completion among young adults (ages 25-44) in 2000, and only in the case of manufacturing has the coefficient dropped substantially over time (Table 4). Part of the explanation is the legacy from the past high dropout rates. Industry employment in 1970 accounts for almost as much variance in the 2000 high school completion measure as does the 2000 industry employment. For all three industries, this legacy may be compounded by a net loss of young adult high school graduates through out-migration. The $\log _{e}$ of employment change 1990-2000 has strong negative partial correlations (controlling for the other industries) with the 2000 proportions in agriculture $(r=-.20)$, mining $(r=-.32)$, and manufacturing $(r=-.25)$. Counties that still have high proportions of employment in these industries tend to be counties left behind, without new growth.

\section{EVIDENCE FOR STATE POLICY}

While the analysis presented here suggests a self-perpetuating process in high school completion, with teenagers dropping out of school most often where adults in the population have not finished high school, there is considerable variation across county dropout rates not accounted for by this process - or the other economic, social, and institutional factors included in this study. The 2000 analysis, for instance, accounted for only about 40 percent of the county variation in dropout rates (Table 3). School policy, whether at the federal, state, or local level, is predicated on the assumption that schools make a difference. Keeping in mind that the differences reflect other unmeasured factors as well, 
differences in average dropout rates across states, net of socioeconomic conditions, suggest how well different state school systems have done in keeping students in school.

The 1980 and 2000 analyses presented in Table 3 were run with additional dummy variables representing all but one of the states in the region. The coefficients represent state average differences in dropout rates, net of the influence of state differences in young adult high school completion, family structure, recent employment gain, and other factors measured in the study. The original and net (adjusted) dropout rates, expressed as differences from the average across all study counties, are shown in Table 5.

The 1980 data show considerable variation across states, with Kentucky having substantially higher average dropout rates than other states. However, Kentucky also had the lowest proportion of young adults with a high school diploma of all the states. Taking this, the high proportion of mining employment, and other factors into account, the adjusted dropout rate for Kentucky was near the regional average. In contrast, the Louisiana average dropout rate was higher than one would expect, given other conditions in its counties.

In addition, there was considerable shifting in relative position over time. The Tennessee average dropout rate was second to Kentucky's in 1980, but it was 2 percentage points below the regional average by 2000 . Taking adult high school completion and

TABLE 5

Nonmetropolitan County Average Dropout Rates (Age 16-19), by State, Original and Adjusted for County Characteristics ${ }^{1 /}$

\begin{tabular}{|c|c|c|c|c|c|c|c|}
\hline \multicolumn{4}{|c|}{1980} & \multicolumn{4}{|c|}{2000} \\
\hline \multicolumn{2}{|c|}{ Original } & \multicolumn{2}{|c|}{ Adjusted } & \multicolumn{2}{|c|}{ Original } & \multicolumn{2}{|c|}{ Adjusted } \\
\hline SC & -5.3 & SC & -3.6 & VA & -3.5 & $\mathrm{TN}$ & -3.4 \\
\hline OK & -5.1 & VA & -2.2 & $\mathrm{TX}$ & -2.5 & $\mathrm{AR}$ & -2.1 \\
\hline $\mathrm{NC}$ & -2.3 & OK & -1.2 & OK & -2.5 & $\mathrm{TX}$ & -2.1 \\
\hline AR & -2.2 & AR & -1.0 & AR & -2.3 & VA & -2.0 \\
\hline $\mathrm{AL}$ & -1.8 & $\mathrm{NC}$ & -0.9 & $\mathrm{TN}$ & -2.0 & OK & -0.4 \\
\hline VA & -0.9 & $\mathrm{AL}$ & -0.8 & $\mathrm{SC}$ & 1.0 & $\mathrm{KY}$ & 0.6 \\
\hline $\mathrm{TX}$ & -0.9 & $\mathrm{TX}$ & 0.1 & MS & 1.1 & $\mathrm{SC}$ & 1.1 \\
\hline MS & -0.5 & $\mathrm{TN}$ & 0.2 & KY & 1.4 & FL & 1.2 \\
\hline FL & 0.5 & GA & 0.2 & $\mathrm{AL}$ & 1.6 & MS & 1.3 \\
\hline GA & 1.4 & KY & 1.0 & $\mathrm{NC}$ & 1.9 & $\mathrm{AL}$ & 1.7 \\
\hline LA & 1.5 & MS & 1.6 & LA & 3.1 & GA & 2.6 \\
\hline $\mathrm{TN}$ & 3.9 & FL & 1.7 & FL & 3.6 & LA & 2.8 \\
\hline KY & 6.1 & LA & 3.8 & GA & 3.9 & NC & 2.9 \\
\hline Region & 19.5 & & & & 11.8 & & \\
\hline
\end{tabular}


other factors into account, Tennessee appears to have the lowest dropout rates of all the Southern states. North Carolina has moved in the opposite direction, from having among the lowest dropout rates in 1980 to among the highest in 2000. Given other measured conditions in its counties, North Carolina counties actually had the highest dropout rates in the region in 2000, along with Louisiana and Georgia counties. Without other, corroborating data, these results cannot do more than suggest that state policy can make a substantial difference in school outcomes and that some states are doing better than others.

\section{CONCLUSION}

High school dropout rates in the rural South have declined over the past 20 years. However, considerable differences in the proportion of teenagers (ages 16 to 19) out of school and lacking a high school diploma across counties in the rural South persist. The top decile in 2000 (18.5 percent) was over three times as high as the bottom decile (5.3 percent). This paper has drawn on Smith's (1989) thesis of the local perpetuation of low educational achievement to explore the differences in dropout rates across counties in the rural South.

The study findings were largely consistent with Smith's (1989) thesis. Across the study period, there was a strong association between the proportion of young adults who had not completed a high school degree and the proportion of teenagers who had dropped out of high school. This association could not be explained by local poverty rates or family structure, two attributes that have frequently been used as explanations of high school noncompletion. In the present study, the poverty rate had no association with teen-age dropout rates once other county attributes were taken into consideration. Moreover, despite the spread of television and the Internet, despite school programs such as Head Start, and despite the substantial increases in the Hispanic populations in some counties, the tendency for county high school dropout rates to perpetuate themselves from one cohort to the next was almost as strong in 2000 as it had been in 1980 .

While industry mattered a great deal in 1970, its importance has diminished over time. There is no evidence at present that agriculture, mining, or manufacturing currently lead to higher dropout rates. At the same time, there is no evidence that changes in manufacturing technologies are acting to reduce dropout rates. Manufacturing is a very diverse industrial sector, having very low skill jobs in food processing as well as fairly high skill jobs in some machinery industries. Manufacturing should perhaps not have been treated as a single industrial sector.

While the strong association between county teen-age dropout rates and low rates of high school completion among young adults suggests that there is an inheritance of low education, the ecological nature of the data in the present analysis does not permit a determination of the levels at which this phenomenon operates. The results could simply reflect household level relationships: education is not highly valued in families where 
parents have little schooling. Previous research at the individual and household level has established this relationship. But the results could also represent community-level factors, where a low value placed on education results in little community support for schools and a culture that does not value school achievement. Whatever the level, the findings of this study suggest that the issue, whether at the household or community level, is not simply one of a lack of family financial resources. Nor can it be ascribed now to local industry structure. Comparisons across states suggest that state policies may weaken the inheritance of low education.

\section{REFERENCES}

Beale, C.L., 1996. “Rural Prisons: An Update,” Rural Development Perspectives 11(2), 25-27.

Bils, M and Klenow, 2000. “Does schooling cause growth?” American Economic Review 90, 1160-83.

Bowles, S. And Gintis, H. 1976. Schooling for Capitalist America: Educational Reform and the Contradictions of Economic Life. New York: Basic Books.

Coleman, J.S., 1988. "Social Capital in the Creation of Human Capital," American Journal of Sociology 94, 95-120.

De Young, A., 1985. "Economic Development and Educational Status in Appalachian Kentucky,” Comparative Education Review 29, 27-67.

, 1991. "Economic Underdevelopment and Its Effects on Formal Schooling in Southern Appalachia," American Educational Research Journal 28(1), 297-315.

Duncan, C.M., 1999. Worlds Apart: Why Poverty Persists in Rural America. Yale University Press: New Haven.

Ghelfi, L.M. and T.S. Parker, 1998. "A County-Level Measure of Urban Influence," Rural Development Perspectives 12(2).

Gibbs, R.M., 1998. "College Completion and Return Migration among Rural Youth," in R.M. Gibbs, P.L. Swaim, and R. Teixeira (eds.), Rural Education and Training in the New Economy: The Myth of the Rural Skills Gap. Iowa State University Press: Ames.

Greenberg, E.J. and R. Teixeira, 1998. "Educational Achievement in Rural Schools," in R.M. Gibbs, P.L. Swaim, and R. Teixeira (eds.), Rural Education and Training in the New Economy: The Myth of the Rural Skills Gap. Iowa State University Press: Ames.

Israel, G.D., L.J. Beaulieu, and G. Hartless, 2001. "The Influence of Family and Community Social Capital on Educational Achievement," Rural Sociology 66, 43-68.

Lichter, D.T., L.J. Beaulieu, J. Findeis, and R.A. Teixeira, 1993. "Human Capital, Labor Supply, and Poverty in Rural America,” in Rural Sociology Task Force on Persistent Rural Poverty, Persistent Poverty in Rural America. Westview Press: Boulder, CO.

McGranahan, D.A., 2001. "The Importance of Manufacturing in the Rural South," The Rural South: Preparing for the Challenges of the $21^{\text {st }}$ Century, No. 22. Southern Rural Development Center. , 1999. "The Geography of New Manufacturing Technology: Implications for the Nonmetropolitan South,” Southern Rural Sociology, 15, 84-103. 
National Center for Education Statistics, 2003. The Condition of Education. Washington, D.C. On line at http://nces.ed.gov/programs/coe/2003/section3/indicator17. asp\#info.

Smith, E.D., 1989. "Reflections on Human Resources in the Strategy of Rural Economic Development," Review of Regional Studies 19, 13-22.

Stallmann, J.I., A. Mwachofi, J.L. Flora, and T.G. Johnson, 1995. “The Labor Market and Human Capital Investment," in L.J. Beaulieu and D. Mulkey (eds.), Investing in People: The Human Capital Needs of Rural America. Westview Press: Boulder, CO.

Wenk, D. and C. Hardesty, 1995. "Family and Household Effects on Educational Attainment,” in L.J. Beaulieu and D. Mulkey (eds.), Investing in People: The Human Capital Needs of Rural America. Westview Press: Boulder, CO. 